\title{
The Results Are In: Identifying Marketing Demographics for a Mid-sized Performing Arts Venue in Multicultural Miami
}

\author{
Tyler Franz \\ Hornets Sports \& Entertainment \\ Armen Shaomian \\ University of South Carolina
}

This paper was presented at the 2018 International Summit of the

Music \& Entertainment Industry Educators Association

March 22-24, 2018

https://doi.org/10.25101/18.34

\section{Abstract}

In 2011, the South Miami-Dade Cultural Arts Center (SMDCAC) opened its doors in a community that had been devastated almost twenty years earlier by Hurricane Andrew. Built in the southern part of Miami-Dade County, this brand new, state-of-the-art venue plays a key role in the economic and cultural development of the area. The venue serves a predominantly African-American and Hispanic community, including a large Caribbean population. The venue is a county-managed building that serves a multidisciplinary and community-gathering role, and it acts as a presenting organization, with performances taking place weekly that range from jazz acts in its multipurpose black box theater to ballet and theater performances in its 961-seat main-stage auditorium. To better understand SMDCAC's patrons and their purchase behavior, an online survey was sent to all active patrons (i.e., those who had bought tickets online and supplied an email address in recent years). Of those who responded $(n=829)$, email marketing led as patrons' most preferred marketing methods $(83.2 \%)$. Further research is necessary to determine bias levels from a strictly online survey, however, those who responded provided a substantial base in determining popularity and patron willingness to spend on various live entertainment program options.

Keywords: performing arts, venue management, arts programming, audience survey, cultural development, ticket management, audience marketing, arts patrons
In 2011, the South Miami-Dade Cultural Arts Center (SMDCAC) opened its doors in a community that had been devastated almost twenty years earlier by Hurricane Andrew. Built in the southern part of Miami-Dade County, this brand new, state-of-the-art venue plays a key role in the economic and cultural development of the surrounding area. The venue serves a predominantly African-American and Hispanic community, including a large Caribbean population. The venue is a county-managed building that serves a multidisciplinary capacity and a community-gathering role, and it acts as a presenting organization, with performances taking place weekly that range from jazz acts in its multipurpose black box theater to ballet and theater performances in its 961-seat main-stage auditorium. To better understand SMDCAC's patrons and their purchase behavior, an online survey was sent to all active patrons (i.e., those who had bought tickets online and supplied an email address in recent years). The survey rubric asked respondents to answer questions centered around five key areas: 1) attendance frequency, 2) amount spent at the venue, 3) advertising and media consumption, 4) commute time, and 5) which shows were most enjoyed. The intent of these questions was threefold. First, they were intended to provide a complete patron overview by providing insight into who comes to the shows. Second, they reveal consumer perception, or what they think of the venue, shows, production, etc. Finally, they illuminate potential next steps by revealing consumer needs and wants, and provide a foundation of ideas for new opportunities.

After gathering a significant amount of data from a sample comprising 829 survey participants, we were able to determine that this venue attracts a very diverse range of consumers. Based on our data, this is an educated consumer base who appreciates learning and culture, even though over 
twenty-five percent of them have no background in music or arts education (see Figures 1 and 2). Looking at hard evidence from survey responses, it can be seen that the large majority of participants prefer to receive correspondence from the venue via email. More than half of the respondents use Facebook, and the median time spent on TV/Radio/ Magazines/Internet consumption was roughly twenty-five hours per week (see Figure 2). Lastly, over three-fourths of the venue's consumers live within a thirty-minute commute to the theater (Figure 2).
Looking at customer perception, the sentiments of the local community towards SMDCAC are overwhelmingly positive. Customers experience joy and anticipation when engaging with the venue, and they trust that they will always have positive experience when in attendance (see Figure 3).

To determine next steps, we first analyzed consumer attendance and spending. Almost seventy-five percent of survey participants attended an event last year, and roughly forty-four percent attended at least three times (Figure 4). While these are excellent statistics, our goal is to find ways

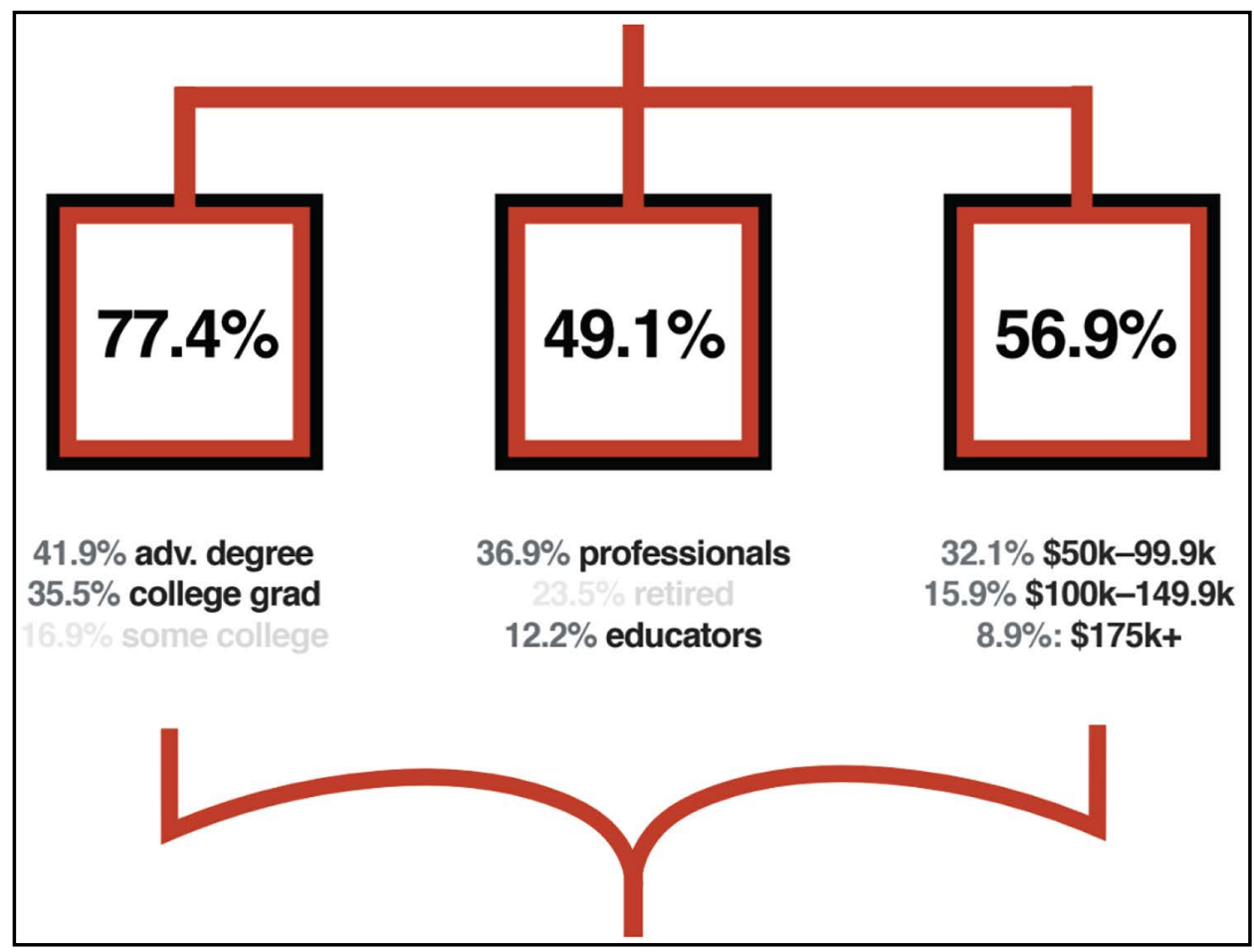

Figure 1. Survey of consumers.

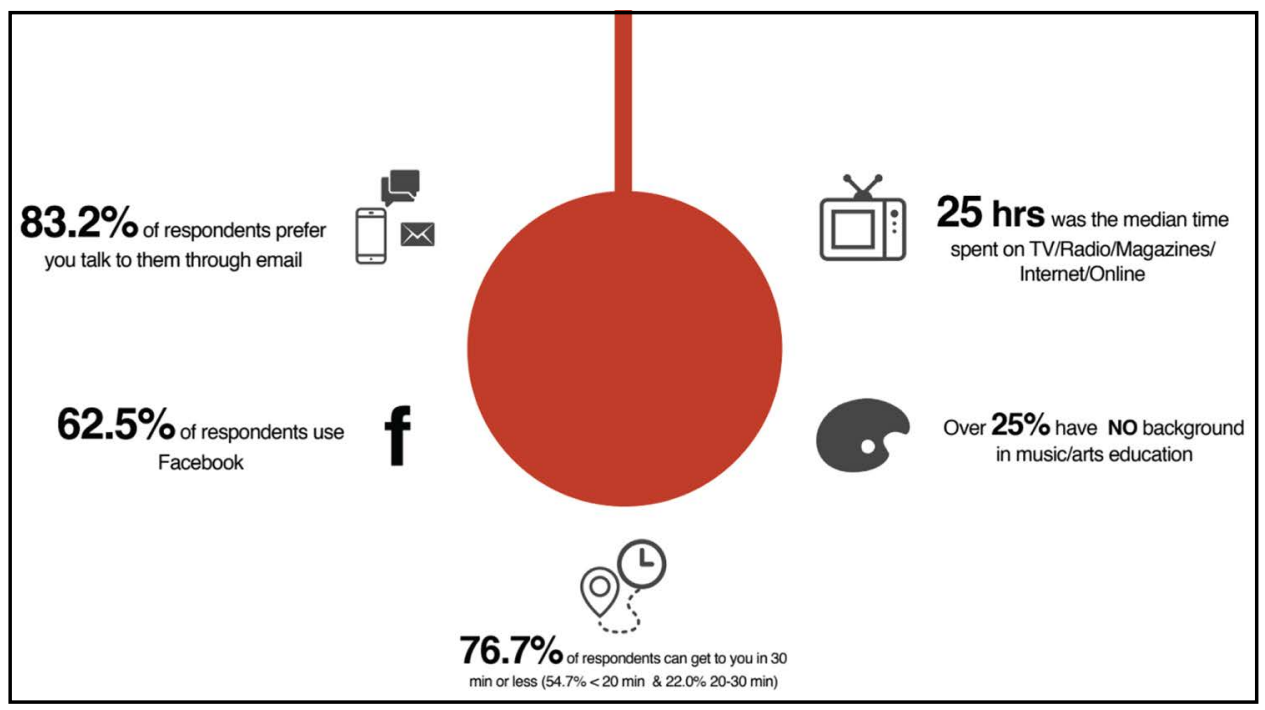

Figure 2. Survey of consumer behavior. 


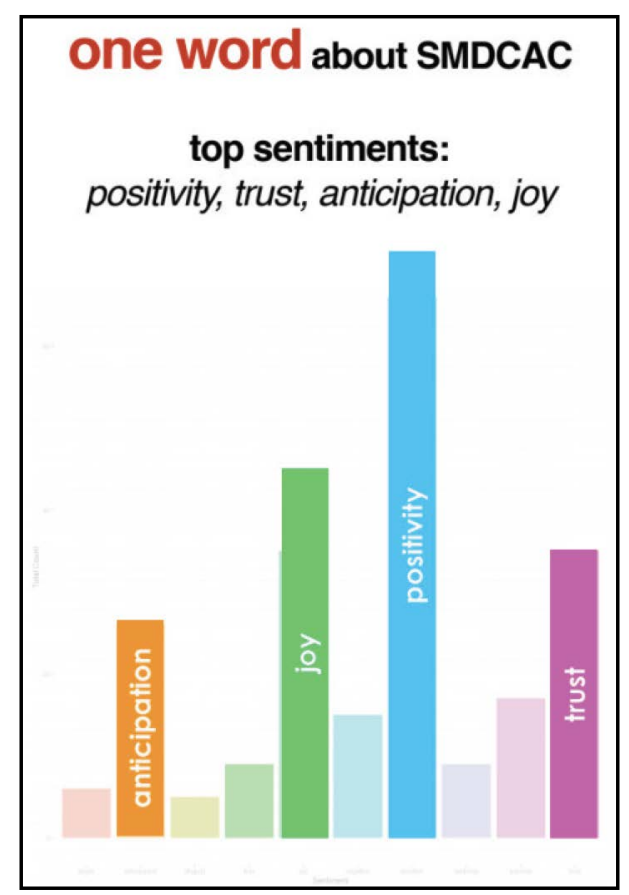

Figure 3. Customer perception.

\section{Preferred program/entertainment options}

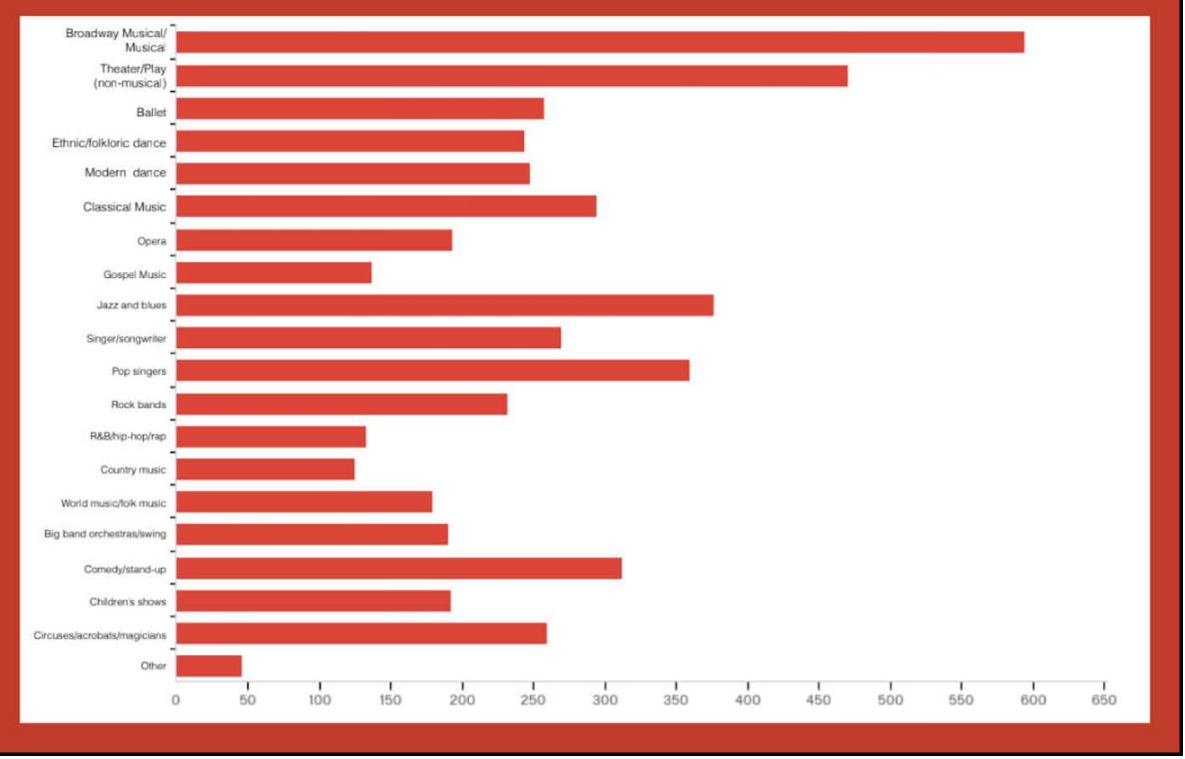

Figure 5. Preferred program/entertainment options.

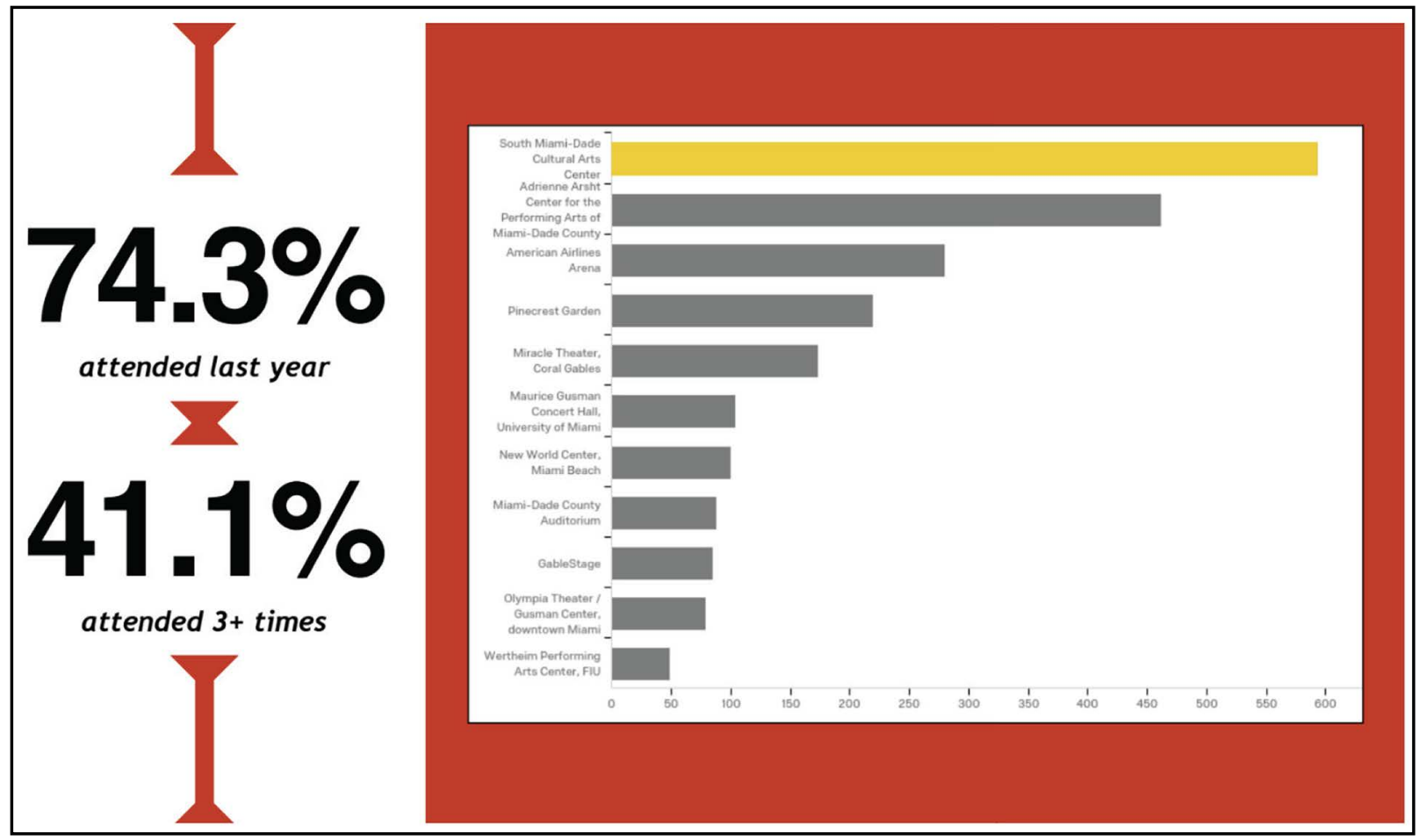

Figure 4. Event attendance.

to continue boosting engagement and attendance by the local community, as this is a demographic that is willing to spend on entertainment - over sixty percent of participants spend more than two hundred dollars per year on entertainment. The survey data will also help us determine potential price points for new shows and ticketing. Participants also indicated what type of program or entertainment options they prefer when attending venue events, and of those types of events, the categories were broken down even further to distinguish which shows specific to each variety were most preferred by consumers (Figure 5). This information will have a great impact on future programming decisions, as 
taking consumer preference into account when engaging artists will likely boost attendance and spending at the venue. Further research is necessary to determine bias levels from a strictly online survey, however, those who responded provided a substantial base in determining who SMDCAC's consumers are, what attracts them to certain events and gets them excited about going to the venue, how much they are willing to spend on various live entertainment program options, and which options they are more willing to engage with in the future

Tyler Franz is a senior business analyst at the Charlotte Hornets and an adjunct professor at the University of South Carolina. He has expertise focused on business development by increasing revenue streams and consumer engagement. Companies and brands he has worked with include Enterprise, McDonald's, the NFL, and more. He holds a Masters in Sport and Entertainment Management from the University of South Carolina and a Bachelor of Science in Exercise Science from Ashland University.

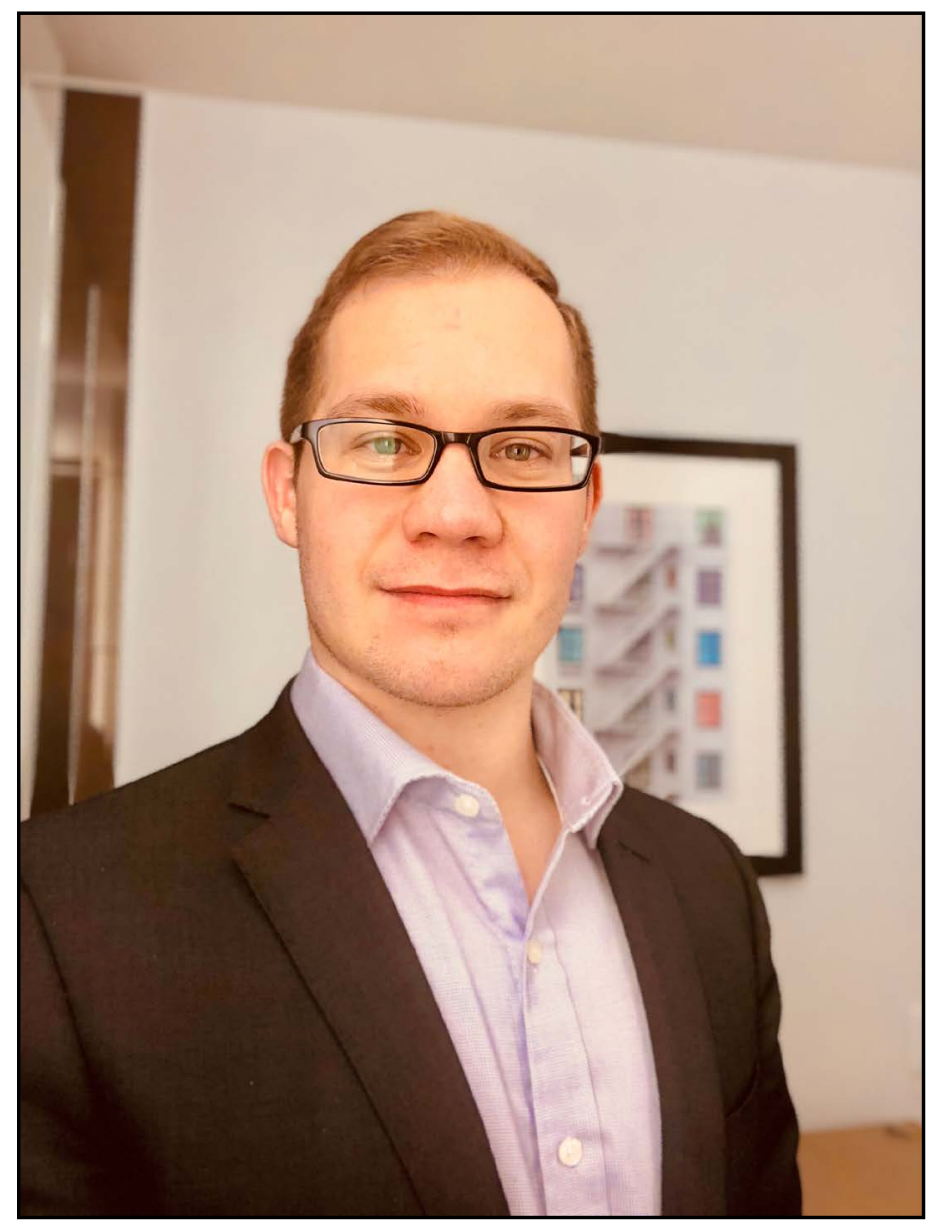

Armen Shaomian, DMA, is an assistant professor in the department of Sport and Entertainment at the University of South Carolina. Dr. Shaomian has extensive background in performing arts management, and project management consulting. He is the founder and CEO of Armenize, Inc., an arts consulting agency specializing in non-profit arts management and foundational strategies. Prior work includes programs manager/associate producer for the National Foundation for Advancement in the Arts (NFAA) and its signature YoungArts program. Dr. Shaomian holds Master's and Doctor of Musical Arts degrees in Accompanying and Chamber Music with cognates in Music Business and Entertainment Industries from the University of Miami. He also holds a Bachelor of Music degree in Piano Performance from Wayne State University. He is an active concert pianist and has performed numerous concerts at venues in Europe and the United States. He has authored a book on Swedish National Romantic Music and his piano recordings of composer Hugo Alfvén are featured on Vax Records' Vaxholm - Ett Dubbelnöje.

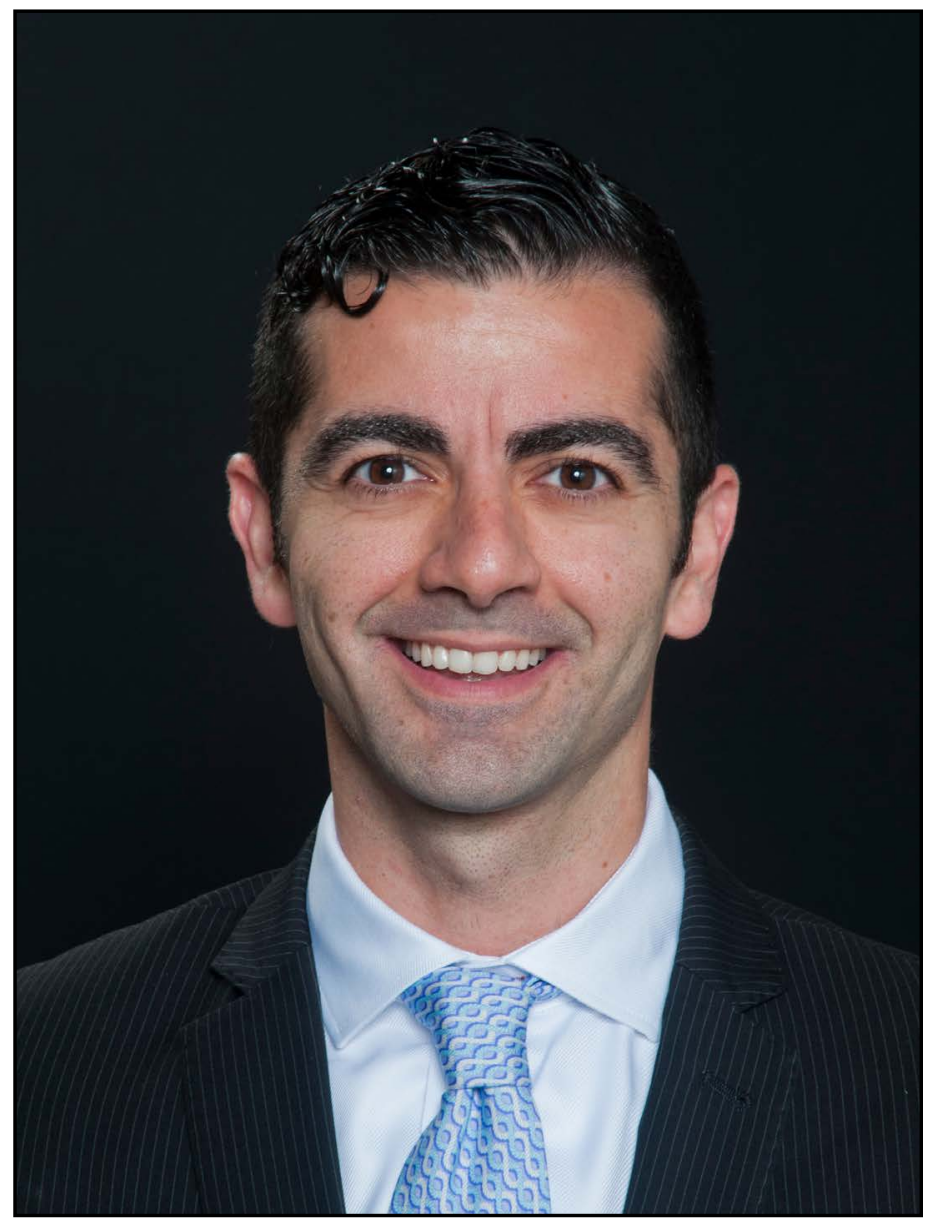




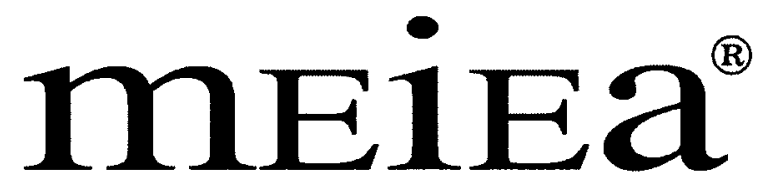

MUSIC \& ENTERTAINMENT INDUSTRY

EDUCATORS ASSOCIATION

\section{PROCEEDINGS OF THE \\ 2018 INTERNATIONAL SUMMIT}

OF THE

\section{MUSIC \& ENTERTAINMENT INDUSTRY EDUCATORS \\ ASSOCIATION}
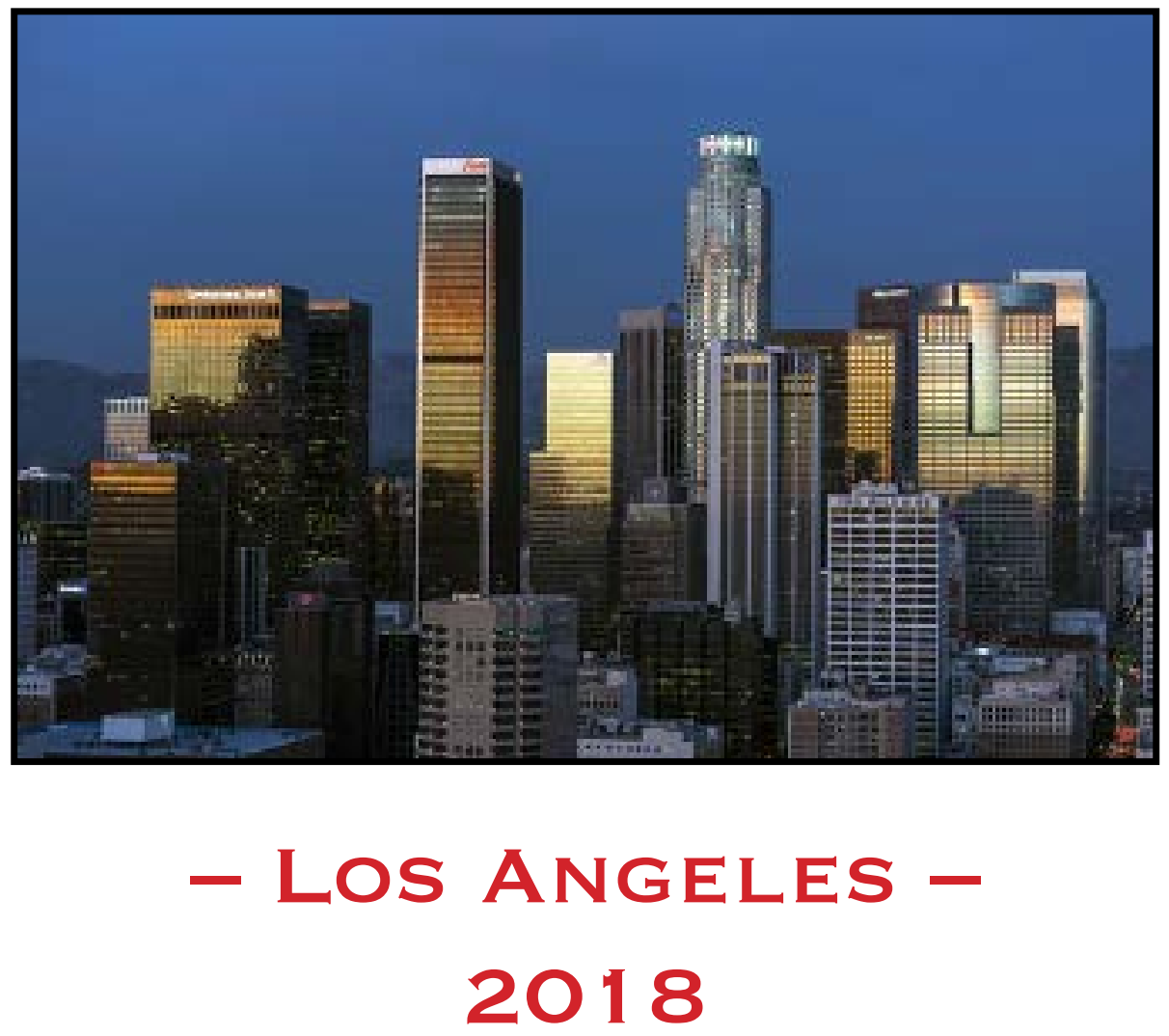

March 22 - 24, $2018 \cdot$ Embassy Suites by Hilton - Los Angeles/Glendale 